\title{
AUTOMATIC IDENTIFICATION OF THE GEOMORPHOLOGIC AND MORPHOTECTONIC FEATURES OF THE SOUTH CRETAN MARGIN, USING OBJECT BASED IMAGE ANALYSIS
}

\author{
Kouli R. ${ }^{1}$, Argialas D. ${ }^{1}$, Nomikou P. ${ }^{2}$ and Lykousis V. ${ }^{3}$ \\ ${ }^{1}$ Laboratory of Remote Sensing, Department of Surveying, School of Rural and Surveying \\ Engineering, National Technical University of Athens, Greece, revekouli@hotmail.com, \\ argialas@central.ntua.gr \\ ${ }^{2}$ Department of Geology, University of Athens, Panepistimioupoli Zografou, 15784 Athens, \\ Greece,evinom@geol.uoa.gr \\ ${ }^{3}$ Inst. of Oceanography, Hellenic Centre for Marine Research, Anavyssos, Greece, \\ vlikou@hcmr.gr
}

\begin{abstract}
This paper is focused on the study of the South Cretan Margin, from a Digital Seabed Elevation Model, by employing Object Based Image Analysis. The goal is the automatic extraction of geomorphological and morphotectonic features based on morphological criteria and topological relations. A Digital Seabed Elevation Model of $150 x 150$ meters resolution was employed. At first, slope, curvature, planform curvature, profile curvature and Topographic Position Index were derived from this DSEM. Five different layers of segmentation were created in order to extract the final geomorphological classes, Ptolemy trough, intraslope basins, main basins, small basins, continental shelf, plains, continental slope, escarpments, canyons, spurs, discontinuities, fault like and fault surface. The results were evaluated quantitatively, through the established indices Completeness, Correctness and Overall Quality. For computing these indices, it was necessary to digitize the boundaries of the objects derived by photo-interpretation. Then, the computation of the above indices, took place by comparing the results of digitized photo-interpretation boundaries, to the extracted feature boundaries through OBIA analysis (in shapefile). It is worth noting that, the results of the evaluation are quite satisfactory. Thus, the developed OBIA method is considered successful.
\end{abstract}

Keywords: Digital Seabed Elevation Model (DSEM), geomorphometry, submarine canyons, fault, fault surface.

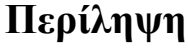

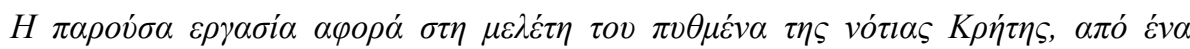

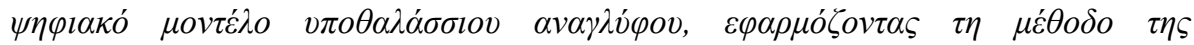

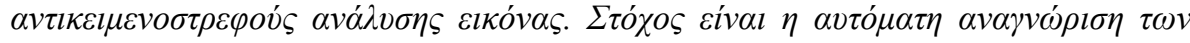

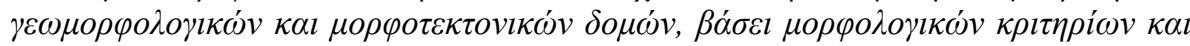

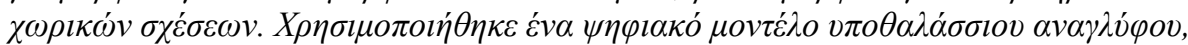

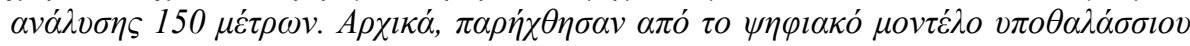




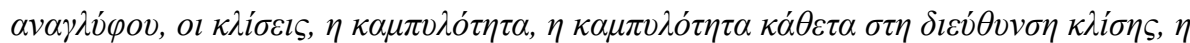

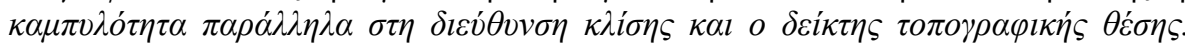

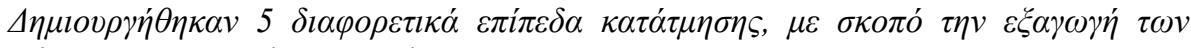

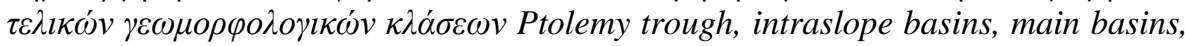
small basins, continental shelf, plains, continental slope, escarpments, canyons,

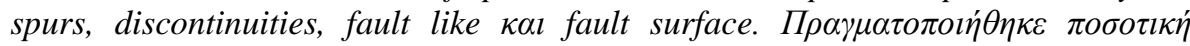

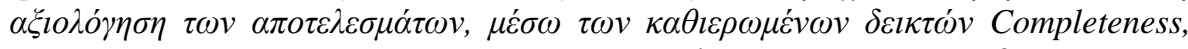

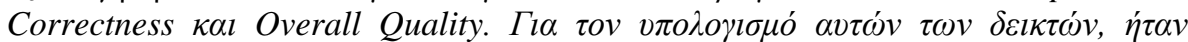

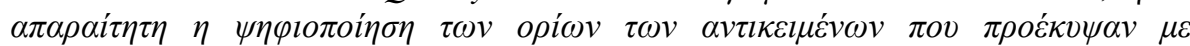

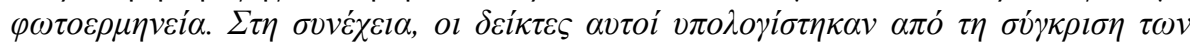

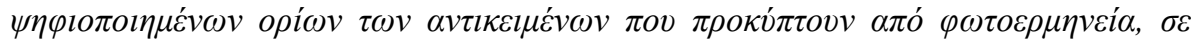

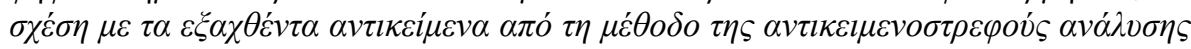

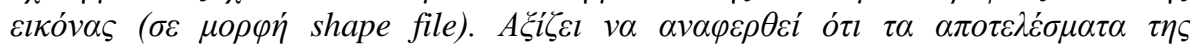

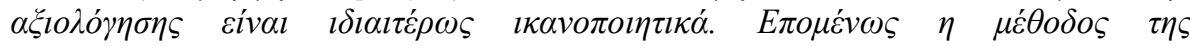

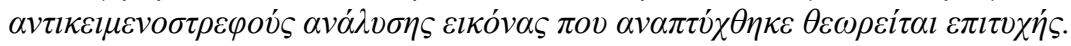

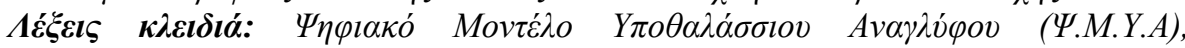

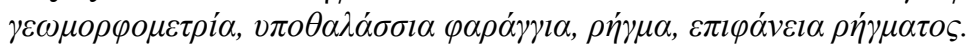

\section{Introduction}

The Hellenic Orogenic Arc is formed along the convergent plate boundary of the northwards subducting African plate underneath the active margin of the European plate (McKenzie, 1972; Le Pichon and Angelier, 1979). The southern Cretan margin is in one of the most seismically active fore-arc regions in Europe (Papazachos et al., 2000; Bonhoff et al., 2001, 2005). According to Kokinou et al. (2012) bathymetric, seismic- reflection and fault plane solution data were used to identify the main tectonic features on the margin, correlating their evolution with the main sedimentary sequences recognized on Crete (Figure 1). The fore-arc setting of Southern Crete is a region of predominantly oblique movement above well-defined detachment zones of convergent tectonic plates. Papanikolaou and Royden (2011) suggest that the southern Hellenic arc is in a state of rapid transition, experiencing an increase in subduction rate toward a steady state rate of not less than $\sim 60 \mathrm{~mm} / \mathrm{yr}$. Model results argue that, at present, $\sim 300 \mathrm{~km}$ of oceanic lithosphere has been subducted beneath the Peloponnesus section of the Hellenides, and $\sim 450 \mathrm{~km}$ beneath the Crete section of the Hellenides. Tiago et al. (2007) analyze 9.5-kHz long-range sidescan sonar (OKEAN), seismic reflection and sediment-core data in the two tectonic troughs south of Crete and reveal eight different types of stratigraphic contacts on basin-margin highs, and basinal areas showing significant changes to the margin's configuration occurred in association with the post-Alpine tectonic and eustatic episodes affecting the Eastern Mediterranean.

The last decade, a new approach called Object Based Image Analysis (OBIA) integrated low level image analysis methods, such as multiresolution image segmentation algorithms, with high level classification methods, such as fuzzy knowledge-based systems (Blaschke, 2010). Within this approach, the low level image analysis produces primitive image objects, while the high level processing classifies these primitives into meaningful domain objects (Benz et al., 2004). In this effort, through the OBIA approach different layers of segmentation were created in order to extract some of the geomorphological classes, i.e. continental slope, canyons and spurs.

\section{Physical Setting}

The very detailed illustration of the swath bathymetry and morphology of the South Cretan Margin reflects the offshore active tectonics and faulting of the seafloor and the overall deformation since Middle Miocene, in association with the general extension of the South Aegean region. Tectonic and neotectonic movements result to vertical movements and strike slip faulting, which have 
produced a complicate morphotectonic structure with diverse canyons and valleys superimposed on elongated, fault-controlled basins (Lykousis et al., 2006).

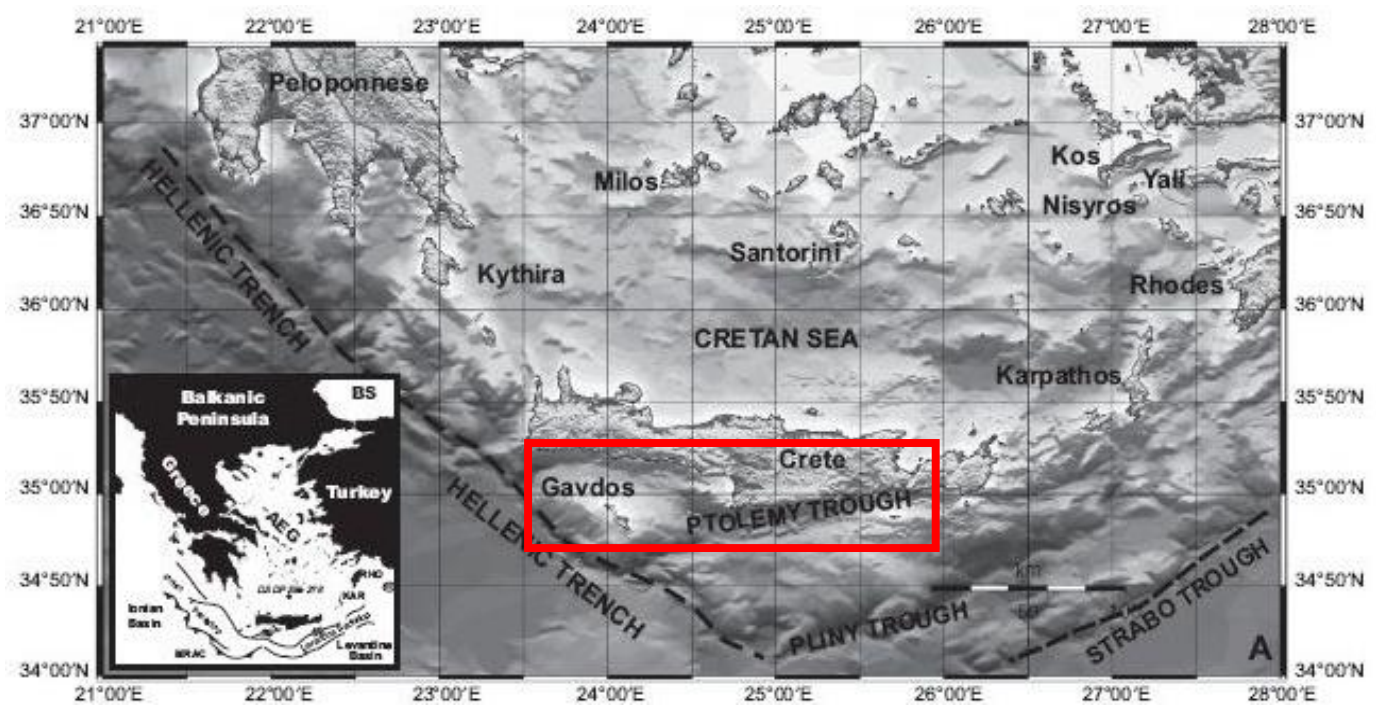

Figure 1 - Bathymetry of the Cretan and Libyan Seas, surrounding the island of $\mathrm{C}$ rete (Kokinou et al., 2012). The red box indicates the study area.

Nomikou et al. (2015) claim that one of the most dominant geomorphological structures of the southwest Cretan slope is the submarine Samaria Canyon (Western Cretan Trough) which is characterized by high relief steep walls and V-shaped cross sections. Despite the fact that, the trough trends predominantly northeastward, with a central axis oriented from east to west, the head displays a north-trending hook termination on the continental shelf. The minimum depth of its axis is 1400 $\mathrm{m}$. In addition, abrupt alternation in the axial trend of the canyon is observed, accompanied by sharp changes in axial gradient and in the geometry of the canyon profile, which ends in a flat area of 3600 m depth.

From Paleochora up to Sindonia, numerous small canyons trending N-S crosscut the steep Cretan southern margin, that reaches the $2000 \mathrm{~m}$ isobath. These are transversal to the main direction of the slope, that is E-W. Furthermore, the detailed bathymetric map reveals the morphology of several troughs, which are bordered by steep slopes and cut by transverse channels. Their flat bottom may reach up to $3000 \mathrm{~m}$ water depth. The most characteristic one, Ptolemy trough (eastern South Cretan Trough), is located in the central southern margin, south of Messara basin. It has a main central axis orientated ENE-WSW, a maximum depth of $2600 \mathrm{~m}$ and is bounded by E-W fault zones.

On the other hand, Gavdos Rise occupies a major part of the South Cretan Margin. It is bordered by longitudinal troughs with steep slopes. Two intraslope basins are also distinguishable at the southwestern part of the Rise, with depths 1100 and $2000 \mathrm{~m}$ respectively. The gentler slopes of the Rise are relatively channel-free with low morphological values.

In such a setting, the fault-bounded continental slope of Crete effectively separates a region of uplift (Crete) from subsiding troughs to the south (Kokinou et al., 2012).

\section{Materials and Methods}

The swath bathymetric survey of the South Cretan Margin was conducted during the HERMES-1 (May-June 2005) and HERMES-2 (September-October 2005) cruises onboard R/V AEGAEO using the $20 \mathrm{kHz}$, SEABEAM 2120 system. High-resolution multibeam bathymetry outlines in unprecedented detail the shape and the morphological features of the region (Nomikou et al., 2015). 
Morphological and morphotectonic analysis of the seafloor is considered a rather tedious and time consuming task requiring expertise. The present work is based on OBIA which is a method that offers the advantage of multi-layer image analysis contrary to pixel based methods that ignore the concepts of neighborhood, hierarchies and scale (Burnett and Blaschke, 2003). The idea behind OBIA is to segment the image into a network of homogenous primitive objects at any chosen resolution forming hierarchical levels of segmentation. These objects serve as building blocks and information carriers for the subsequent classification process (Benz et al., 2004). The classification process assigns a class to each image object based on a fuzzy knowledge base. The result of the classification is a network of image objects with concrete attributes, topological relations and relations to the classes in the class hierarchy (Benz et al., 2004). Another important part of the analysis is the classification based segmentation which uses the knowledge developed in the classification process to form new objects or correct the shape of existing image objects through refinements or merges.

Object Based Image Analysis is still an active area of research (Blaschke, 2010). Studies on advanced segmentation methods (Carleer et al., 2005), on advanced classification methods (Gamanya et al., 2007; Aplin and Smith, 2008; Tzotsos and Argialas, 2008), on remote sensing applications (Lucas et al., 2007; Hofmann et al., 2008; Bhaskaran et al., 2010) and on scale-space representation (Tzotsos et al., 2011) are recent efforts. The OBIA approach includes two basic procedures: segmentation and classification and in this study it was applied through the eCognition Developer Trial 8.7 software.

A DEM of the seabed in the area of South Crete, Greece, with a resolution of $150 \mathrm{~m} \times 150 \mathrm{~m}$ was employed. The DEM was created through processing multibeam echo sounder data of the area. The first step in this approach was the creation of certain derivatives of the DEM (9 layers), especially: elevation, slope, aspect, curvature, planform curvature, profile curvature, topographic position index, with radius of 300m TPI300, 1000m TPI1000 and 5000m TPI5000.

The presented OBIA approach was designed by a trial and error effort to include five different levels of resolution. The objects on all levels were designed to represent different scales of seabed features and to facilitate the extraction. Creating a bottom to top approach, larger objects were created in lower levels and therefore larger scale geomorphological features were classified, while in higher levels the finer scale features were identified. For each level a set of classes was designed with the name of each class containing the number of the level that it was designed for i.e. continental slope (2) for the level 2.

Different segmentation parameters can be applied creating different objects in various resolution levels of hierarchy in the same image. Objects in higher levels are referred to as super-objects, while in lower levels as sub-objects, creating a hierarchical objects network. Subsequently, the user defines the classes of interest assigning selected attributes and their values through fuzzy membership functions to each class.

\section{Results}

\subsection{Level 0 and Level 1}

Objects on level 0 , the highest level, were created only, in order to separate the land from the sea. Objects on level 1, were created, in order to separate the background (1) of the image (no data area), from the actual DSEM, called study area (1). For this separation, only the Elevation feature was used. No further description of it will be made, since it is of no geomorphological or topographical interest.

\subsection{Level 2}

The objects on level 2 were created using a smaller scale parameter of 10 , and shape 0.1 and compactness 0.5 , so as to extract smaller features. The only image layer used was the slope. 
The morphological slope map, was created primarily, in order to distinguish objects belonging to classes: flat area (2) $(<1 \%)$, mild slope area (2) (1-4\%), moderate slope area (2) (4-15\%) and steep slope area $(2)(>15 \%)$.

Classes flat area (2) and mild slope area (2) included objects with slope values smaller than 4\%, in the thematic level of the DSEM. By applying the algorithm merge region, these classes were composed of a single object. Furthermore, in order to identify objects which eventually would be categorized as depressions (2) and not depressions (2), the Topographic Position Index (TPI) feature (TPI1000, TPI5000) was used. The objects of class depressions (2) have negative values of TPI, as they are at lower elevations than their neighboring objects.

Based on the existence of super-objects belonging to class depressions (2), the following classes of sub-objects were derived: trough (2), intraslope basins (2), main basins (2) and small basins (2), based on the features Asymmetry, Area and Relative Border to. The orange color trough indicated in Figure 2, corresponds to the unique trough of the area called Ptolemy Trough, as it is also indicated in Figure 1.

Moreover, based on the existence of super-objects belonging to class not depressions (2), the following classes of sub-objects were derived: continental shelf (2) and plain (2), based on the feature Distance to. Based on the existence of super-objects belonging to classes moderate slope area (2) and steep slope area (2), the following classes of sub-objects were derived: continental slope (2) and escarpment (2), based on the features: Relative Border to and Distance to.

Consequently, for the classification of Level 2, a class hierarchy was created, containing the following classes: continental slope (2), escarpment (2), continental shelf (2), plain (2), trough (2), intraslope basins (2), main basins (2) and small basins (2) (Figure 2).

\subsection{Level 4}

The purpose of Level 4 was the derivation of the hydrographic network in the study area. Thus, classes canyons (4) and spurs (4) were created. In the previous levels, it was not possible to identify those categories, due to their small size.

For the segmentation of Level 4, the objects were created using the smallest scale parameter of 1. Shape was set to 0.1 and compactness to 0.5 , without particular importance due to pixel size of objects. Segmentation took place by assigning weigh 1 to both slope and planform curvature thematic layers.

Classes canyons (4) and spurs (4) were derived based on the features Planform Curvature and Slope. Using the feature view tool, through a trial and error effort, the crucial value of Mean planform curvature feature, was revealed and the separation between the two classes, through fuzzy membership functions, was achieved. Class gently sloping area (4) was created in order to distinguish objects belonging neither to canyons (4), nor to spurs (4).

Consequently, for the classification of Level 4, a class hierarchy was created containing the following classes: canyons (4), spurs (4) and gently sloping area (4) (Figure 3). 


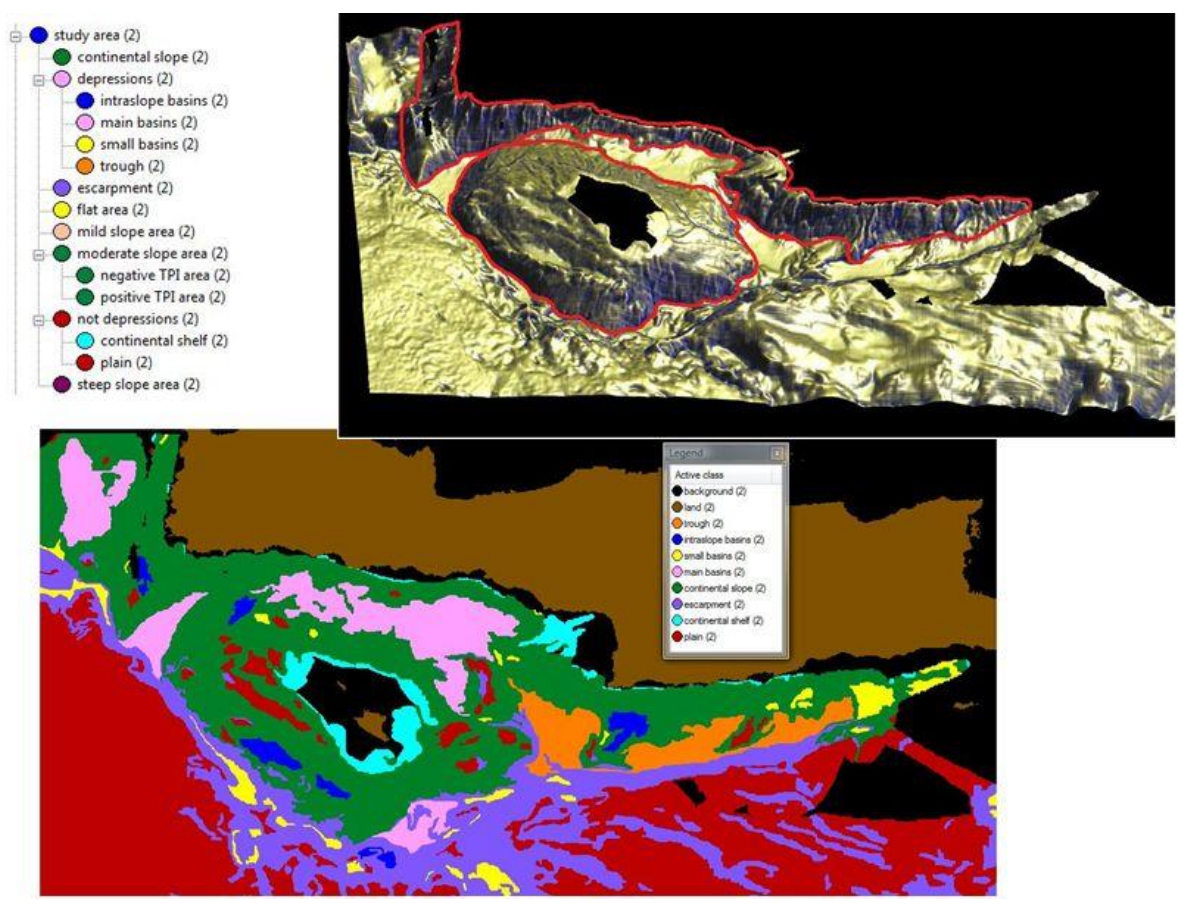

Figure 2 - Classification results in Level 2 and 3D display of study area (separation of continental slope and depressions was highlighted in 3D model).

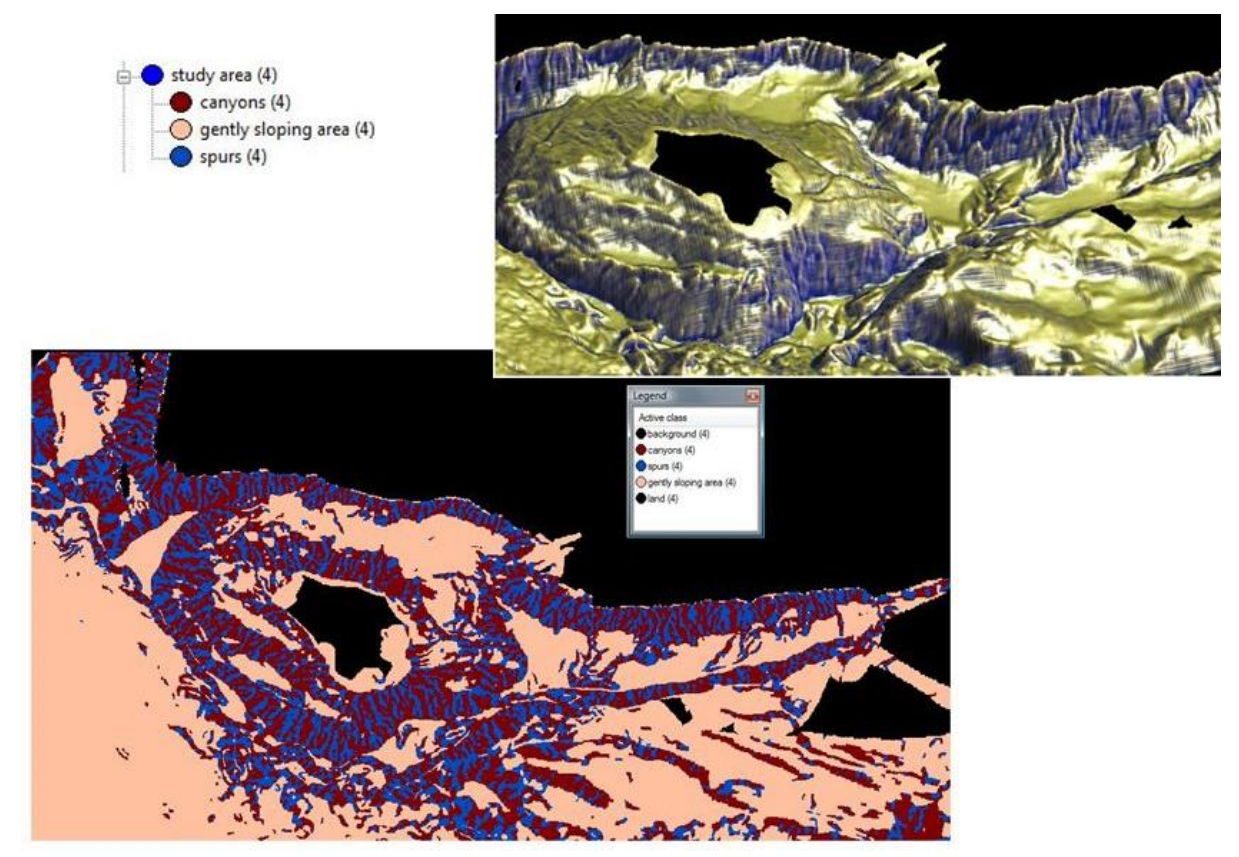

Figure 3 - Classification results in Level 4 and 3D display of study area (separation of canyons and spurs was highlighted in 3D model). 


\subsection{Level 5}

The purpose of Level 5 was the derivation of the morphotectonic lineaments, in the study area. That's why, classes discontinuities (5), fault like (5) and fault surface (5) were created. In the previous levels, it was not possible to identify those categories, due to their small size.

For the segmentation of Level 5, the objects were created using the smallest scale parameter of 1, while shape was 0.1 and compactness was 0.5 , without particular importance, due to pixel size of objects. Segmentation took place by assigning weigh 1 to both slope and profile curvature thematic layers.

Classes discontinuities (5) and fault like (5) were derived based on the features Profile Curvature and Slope. Using the feature view tool, through a trial and error effort, the separation between the two classes, through fuzzy membership functions, was achieved. Faults were characterized as fault like because the extracted faults are based on geomorphometric and topologic relations, without the use of seismic data confirming the existence of actual faults.

The class fault surface (5) was derived based on the features Relative border to discontinuities (5), Relative border to fault like (5) and Slope. Fault surface, generally, is called the surface along which the two blocks move respectively to each other, so in this case is the area disclosed between discontinuity and the trace of the fault. Class other (5) was created in order to distinguish objects belonging neither to discontinuities (5), nor to fault like (5) or to fault surface (5).

Consequently, for the classification of Level 5, a class hierarchy was created, containing the following classes: discontinuities (5), fault like (5), fault surface (5) and other (5), (Figure 4).

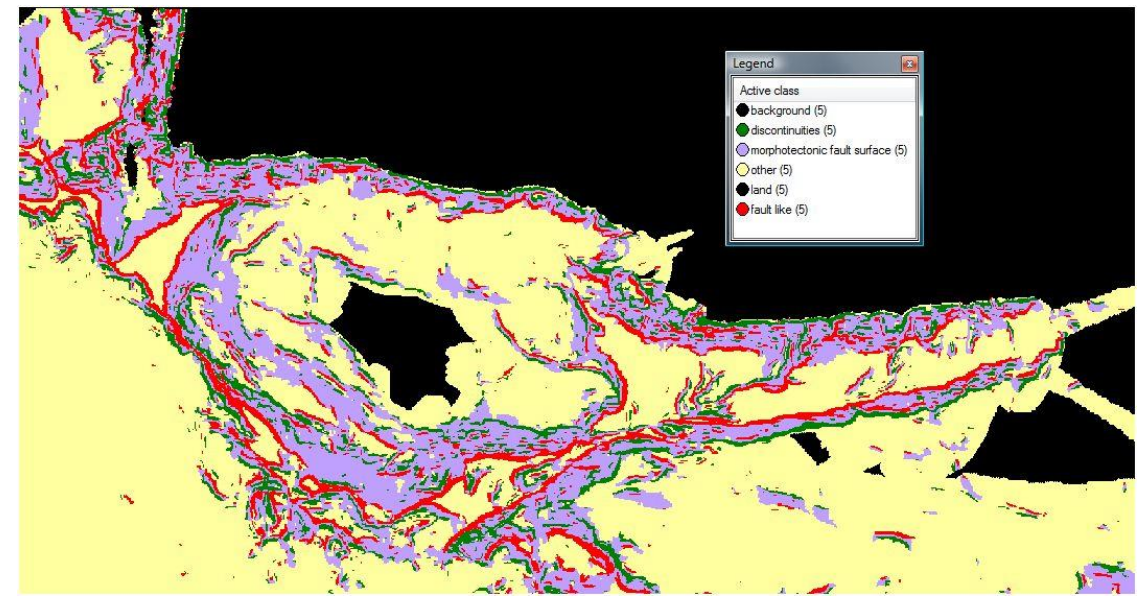

Figure 4 - Classification results in Level 5.

\section{Discussion}

For the quantitative evaluation of extracted objects, the established indices Completeness, Correctness and Overall Quality (Mariano et al., 2002) were employed. For computing these indices, it was necessary to digitize the boundaries of the objects derived by photo-interpretation. Digitization was applied in the open source software QGIS. Then, the computation of the above indices, took place by comparing the results of digitized photo-interpretation boundaries, to the extracted feature boundaries through OBIA analysis (in shapefile).

The classification result of trough (2) (blue polygon) was compared with the result derived by photointerpretation (pink polygon), as shown in Figure 5. The values of the indices were computed as Completeness $=80 \%$, Correctness $=96 \%$, Quality $=77 \%$. The two polygons were matched almost entirely, that's why the results were very satisfying (Figure 5). 


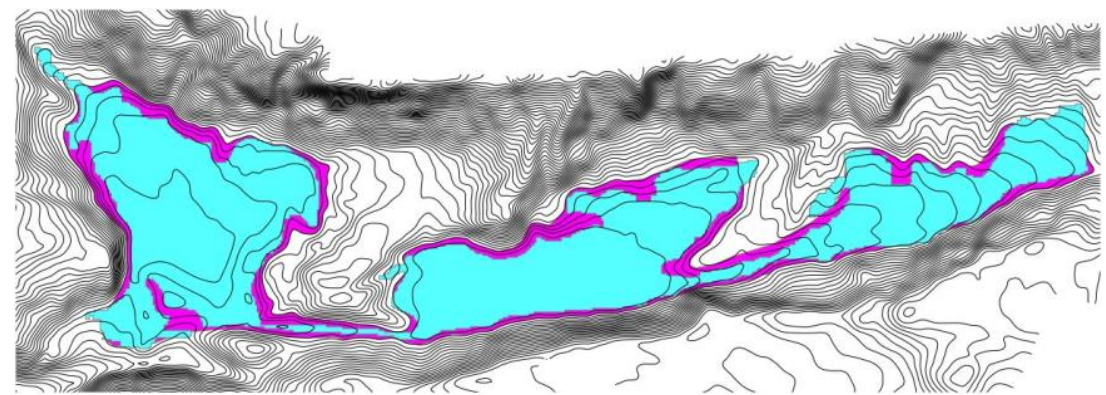

Figure 5 - The quantitative evaluation of the class trough (2).

The classification result of main basins (2) (blue polygon) was compared with the result derived by photo-interpretation (pink polygon) as shown in Figure 6 . The values of the indices were computed as Completeness $=83 \%$, Correctness $=87 \%$, Quality $=74 \%$. Minor divergences were occurred on the two big basins, in the $\mathrm{N}$ and NW study area. But, in general, the overall results were very satisfying (Figure 6).

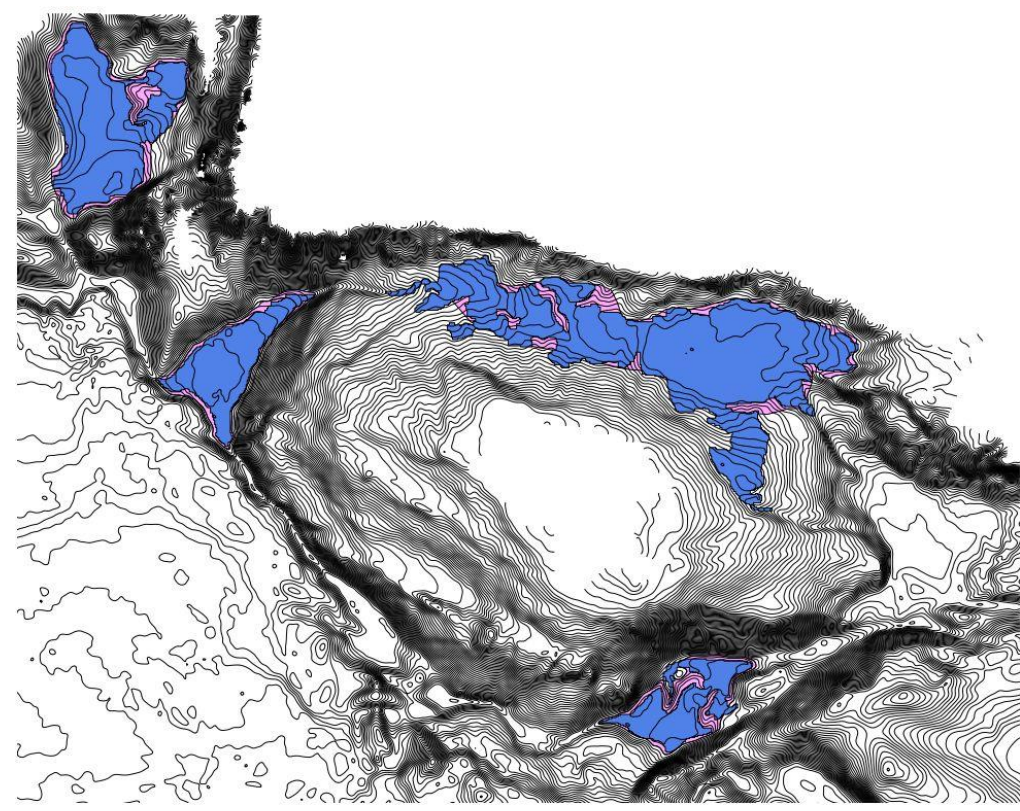

Figure 6 - The quantitative evaluation of the class main basins (2).

The classification result of continental slope (2) (red polygon) was compared with the result derived by photo-interpretation (green polygon), as shown in Figure 7. The values of the indices were computed as Completeness $=92 \%$, Correctness $=74 \%$, Quality $=69 \%$. Some objects were probably misclassified to class continental slope (2), although they belonged to class escarpment (2). That commission error was due to the limits of the values of the feature Distance to land. Despite these errors, the OBIA analysis gave acceptable results (Figure 7). 


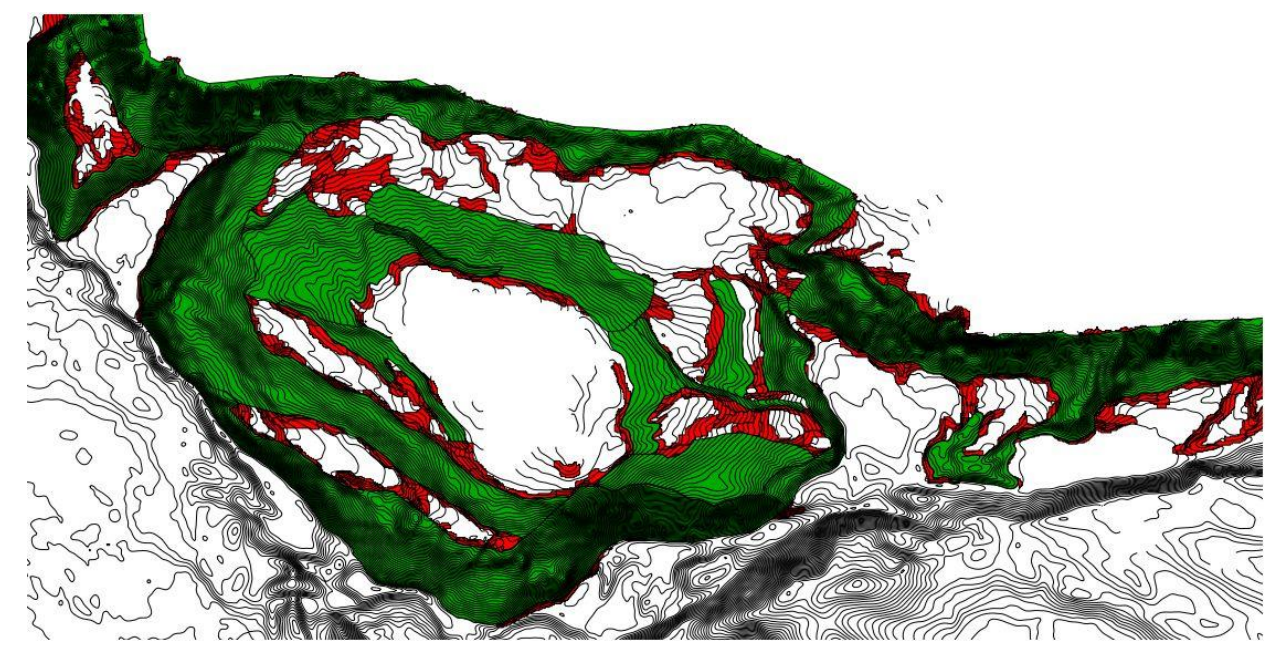

Figure 7 - The quantitative evaluation of the class continental slope (2).

\section{Conclusion}

This work has shown that the developed OBIA approach through a digital elevation model is a useful tool for the automated extraction of geomorphological and morphotectonic features of the seabed. The knowledge of the eCognition software, the study of the area, the experience and ability of photointerpretation and background knowledge in geomorphometry were necessary for the OBIA analysis to be successful.

Segmentation to large objects was employed to distinguish huge regions such as land and sea. Segmentation to medium objects was employed to distinguish landforms such as depressions, trough, basins, continental shelf and continental slope. While segmentation to small objects, was employed for the recognition of faults, lineaments, spurs and canyons.

It is worth noting that the Ptolemy trough (figure 1), as determined by quantitative evaluation of the results, was the landform class extracted with the highest accuracy (Correctness 96\%). This seems reasonable, because this specific landform is easily distinguishable due to the abrupt transition in slope angles.

Moreover, discontinuities (5), and fault like (5), were the landform classes detected with the lowest accuracy (Correctness 67\%). The photo-interpretation and the digitization were extremely difficult because of the specific linear shape of those morphotectonic features.

The OBIA approach is expected to be even more successful and precise on identifying geomorphological and morphotectonic features with a better resolution DSEM, or with AUV data and it would be even more interesting in applying this approach to sidescan sonar images.

\section{Acknowledgements}

Matina Alexandri and Dionissis Ballas are gratefully acknowledged for their important and effective contribution during these cruises. We also thank the scientific and technical crew of the RV Aegeao for support during the 2005 Hermes- 1 and Hermes- 2 cruises (Cretan margin). The bathymetric data presented in this paper was funded by the EU programme HERMES (GOCE-CT-2005-511234-1).

\section{References}

Alves, T.M., Lykousis, V., Sakellariou, D., Alexandri, S. and Nomikou, P., 2007. Constraining the origin and evolution of confined turbidite systems: southern Cretan margin, eastern Mediterranean Sea (3430-36 ${ }^{\circ}$ ), GeoMarine Letters, 27, 41-61. 
Argialas, D. and Tzotsos, A., 2003. "Geomorphological feature extraction from a digital elevation model through fuzzy knowledge-based classification", in remote sensing for environmental monitoring, GIS applications, and Geology II. M. Ehlers (Editor), Proc. of the SPIE International Conference on Remote Sensing, Agia Pelagia, Crete, 23-26 September 2002, 4886, 516-527.

Argialas, D. and Tzotsos, A., 2006. Automatic extraction of physiographic features and alluvial fans in Nevada, USA from digital elevation models and satellite imagery through multiresolution segmentation and object-oriented classification, Proc. of the ASPRS 2006 Annual Conference, Reno, Nevada, 1-5 May, 3-8.

Baatz, M. and Schäpe, A., 1999. Object-oriented and multi-scale image analysis in semantic networks, $2^{\text {nd }}$ international symposium: operationalization of remote sensing, 16(20), 7-13.

Bohnhoff, M., Makris, J., Papanikolaou, D. and Stavrakakis, G., 2001. Crustal investigation of the Hellenic subduction zone using wide aperture seismic data, Tectonophysics, 343(3), 239-262.

Bohnhoff, M., Harjes, H.P. and Meier, T., 2005. Deformation and stress regimes in the Hellenic subduction zone from focal mechanisms, Journal of Seismology, 9(3), 341-366.

Kokinou, E., Tiago, A. and Kamberis, E., 2012. Structural decoupling in a convergent forearc setting (southern Crete, eastern Mediterranean), Geological Society of America Bulletin, doi: 10.1130/B30492.1.

Le Pichon, X. and Angelier, J., 1979. The Hellenic arc and trench system: a key to the neotectonic evolution of the eastern Mediterranean area, Tectonophysics, 60, 1-42.

Lykousis, V., Sakellariou, D., Alexandri, M., Nomikou, E., Stavrakakis, S., Karageorgis, A., Kontogiannis, H., Georgiou, P. and Rousakis, G., 2006. The southern Cretan margin (E. Mediterranean) in the Hermes project, Abstracts of EGU2006 General Assembly, Vienna, Austria, Abstract EGU06-A-10458.

McKenzie, D.P., 1972. Active tectonics of the Mediterranean region Geophys, Journal of the Royal Astronomical Society, 30, 109-185.

Mariano, V.Y., Park, J H., Kasturi, R., Mihalcik, H., Doermann, D. and Drayer, T., 2002. Performance evaluation of object detection algorithms. In: Pattern recognition, 2002, Proc. of the 16th International Conference, 3, 4-9.

Nomikou, P., Lykousis, V., Alexandri, M., Rousakis, G., Sakellariou, D., Lampridou, D., Alves, T. and Ballas, D., 2015. Geomorphologic structures on the south Cretan Margin, Greece, Abstracts of EGU2015 General Assembly, Vienna, Austria, 17, Abstract EGU2015-3568.

Papazachos, B.C., Karakostas, V.G., Papazachos, C.B. and Scordilis, E.M., 2000. The geometry of the Wadati-Benioff zone and lithospheric kinematics in the Hellenic arc, Tectonophysics, 319, 275-300.

Royden, L.H. and Papanikolaou, D., 2011. Slab segmentation and late Cenozoic disruption of the Hellenic arc, Geochem. Geophys. Geosyst., 12, Q03010, doi: 10.1029/2010GC003280.

Siakavara, K. and Argialas, D., 2013. Automated identification of geomorphological and topographical features of the seabed by Object Based Image Analysis of Digital Terrain Models, Zeitschrift für geomorphologie, supplementary issues, 57(3), 63-74.

Trimble, 2011. eCognition Developer 8.7, Reference Book, Trimble München, Germany, 206 pp.

Zevenbergen, L. and Thorne, C., 1987. Quantitative analysis of land surface topography, Earth surface processes and landforms, 12(1), 47-56. 